\title{
The Role of IAU in Facilitating International Cooperation
}

\author{
Ranbir Singh
}

The International Association of Universities (IAU), founded in 1950 under the auspices of UNESCO, is a prominent global association of higher education institutions as well as organisations across the world.

With over 600 members from around the world IAU provides a bridge amongst various member institutions for reflection and sharing of best practices on similar lines. IAU acts as the unique global mouthpiece of higher education to UNESCO and national policy makers, as it also provides an international platform for the leaders of its member institutions and associations. IAU promotes academic linkages among its members by enunciating the fundamental values and principles that support the quest, propagation and purpose of knowledge. The IAU brings out new higher education policy statement, perspectives and practices with special emphasis on values and leadership, encouraging new and innovative methods for association among its institutions.

International organizations, of which IAU has been a very significant partner, have continuously highlighted the importance of higher education institutions (HEIs), especially in the domain of highlighting their global visibility. Apart from other aspects of global relevance, internationalization of higher education at the global level has been of much significance because it helps to narrow down the digital and knowledge divide by reducing the differences between developing and developed countries.

This has been made possible because of a very concerted effort by the IAU through technological knowledge exchanges between different countries of the global north and global south. The IAU has for long realized the important role HEIs can play for promoting development and has been instrumental in impacting social change. Many of the institutional associations world-wide have greatly benefitted through

R. Singh $(\varangle)$

National Law University, Delhi, India

e-mail: vc@nludelhi.ac.in 
the hand-holding support of IAU for promoting and strengthening their international cooperation and academic exchange mechanisms.

The inherent quality of internationalization being networking, sharing, equality among partners etc. has ushered in a new area of promoting excellence through regional and international cooperation in various fields of study and research. Internationalization to a great extent has been able to promote global citizenship in education by the exchange of faculty, students and collaborative research.

IAU's continuous effort has been to bridge the demographic, digital and knowledge divide between countries, and it has played a very significant role through internationalization of HEIs through its various programs and missions.

Internationalization is a very familiar phenomenon in higher education, not just in India but in many other countries. For decades, students have been travelling to other countries for higher education. Similarly, faculty members and research scholars have been going to foreign institutions to teach or undertake research initiatives. In fact, many foreign faculties also spearhead the leadership role along with the responsibility of teaching and research. Therefore, in one form or the other, internationalization has had a direct influence on the way teaching and learning has been carried out, and so has research and institution building.

While to a certain extent universities and other institutions of education have always been influenced by the broader global trends, however, in today's globalized and interconnected world, the importance of collaboration and cooperation cannot be left in a vacuum, and that is where the IAU has been playing a lead role.

ICTs have played a large role in further strengthening international cooperation. However, this has not had the desired impact in bridging the gap between academic institutions in the developed world and those in the developing world. A lot more needs to be done for bridging this divide, and for bringing the higher education institutions in the global south to the level of the institutions in the global north.

Similarly, even in the local context, inequality among national higher education systems has increased in the past decades. The academic world has always been characterized by centres and peripheries. The strongest universities, usually because of their research prowess and reputation for excellence, are seen as centres of excellence (Altbach 2011) and attract the brightest students and faculty, as well as endowments and research funding. There is also an urgent need to promote interdisciplinary education all over but especially in developing countries, where they are lacking. Some of these countries have started encouraging this, and there is a need for further development. Similarly, interdisciplinary and transdisciplinary research also needs to be a priority for all academic institutions.

A number of factors have led to the current revolution in the higher education space. As discussed above, the most important is globalization and the role played by ICTs. We should also not discount massive expansion of higher education and the role played by universities in undertaking significant academic research.

However, we should be mindful of certain challenges, including the rapid privatization of education. The increasingly unaffordable fee charged by some universities and decreasing state support for education in a large part of the world is also a major cause of concern. In current times, a number of institutions are more focused on 
maintaining their legacy and securing a high place in a number of influential world rankings and, in a lot of cases, resemble private corporations with the focus on maximizing revenue and profits. Many universities are losing focus on their foundational vision and the core academic values and are not focusing on the greater welfare of society or the democratization of education.

We must also need to rethink our models of education, since industry 4.0 and today's careers require continuous, lifelong learning. While the idea of lifelong learning is not new, the conditions for lifelong learning have changed significantly, and this need has never been more significant (Østergaard and Nordlund 2019). The new education models must incorporate this change and build a culture that promotes it (Østergaard and Nordlund 2019).

All this requires much greater cooperation between educational institutions, and other relevant stakeholders, including the students, faculty, states and industry. IAU has over the years facilitated international cooperation in the higher education ecosystem in a number of ways, including promoting international student and faculty mobility; promoting cultural and intercultural understanding; establishing academic partnerships with foreign institutions relating to teaching; promoting research collaboration at individual and institutional levels.

The IAU also provides dedicated services to its member institutions by way of its expertise and trends analysis, publications and portals, advisory services, peer-topeer learning and training, conducting events on knowledge sharing, representation and global advocacy in promoting international cooperation and leadership.

The IAU has given special attention to the challenges posed by COVID-19 around the world, providing information on online education and the steps required for keeping our campuses safe. Going forward, there may be a greater reliance on ICTs and online education as a way to make quality higher education accessible and affordable.

The initiatives provided by the IAU have gone a long way in building up confidence between HEIs as well as faculty by convincing everybody that together we can boldly face the situation created by COVID-19, in the interest of everybody affected by the pandemic.

There will be numerous challenges faced by universities and other institutions in the immediate aftermath of COVID-19 and after that with the growth of the digital economy and industry 4.0. Closer collaboration and linkages between these institutions provides a better path forward to deal with these challenges, and IAU will have a much greater role and responsibility to make this happen, as well as to meet the emerging challenges brought about by artificial intelligence and other technologies which may be seen as disruptive.

\section{References}

Altbach, P. G. (2011). Global academic revolution: Implications for India. Journal of Educational Planning and Administration, 25(4), 301-313. 
Østergaard, S. F., \& Nordlund, A. G. (2019. December 19). The 4 biggest challenges to our higher education model - and what to do about them. World Economic Forum. Retrieved from: https://www.weforum.org/agenda/2019/12/fourth-industrial-revolution-highereducation-challenges/ (26.07.2020)

Ranbir Singh is the founder Vice-Chancellor of "National Law University, Delhi" established by the Delhi Government in 2008. He is also member of the Administrative Board of the International Association of Universities (IAU) and a member of the council of the Association of Commonwealth Universities (ACU), London. Randbir Singh has been the founder Vice-Chancellor of NALSAR, University of Law, Hyderabad (1998 to 2008) and he has been a Vice-Chancellor continuously for over 22 years now.

Open Access This chapter is licensed under the terms of the Creative Commons Attribution 4.0 International License (http://creativecommons.org/licenses/by/4.0/), which permits use, sharing, adaptation, distribution and reproduction in any medium or format, as long as you give appropriate credit to the original author(s) and the source, provide a link to the Creative Commons license and indicate if changes were made.

The images or other third party material in this chapter are included in the chapter's Creative Commons license, unless indicated otherwise in a credit line to the material. If material is not included in the chapter's Creative Commons license and your intended use is not permitted by statutory regulation or exceeds the permitted use, you will need to obtain permission directly from the copyright holder.

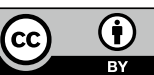

